2 Wall, W J, et al, Transplantation, in press.

3 Williams, R, British Medical fournal, 1970, 1, 585.

${ }^{4}$ Parkes, J D, Murray-Lyon, I M, and Williams, R, Quarterly fournal of Medicine, 1970, 39, 515.

${ }^{5}$ Knill-Jones, R P, et al, New England fournal of Medicine, 1970, 282, 704.

${ }^{6}$ Calne, R Y, British Medical fournal, 1975, 1, 251.

; Abouna, G N, et al, Canadian Medical Association fournal, 1976, 45, 615.

${ }^{8}$ Waldram, R, Williams, R, and Calne, R Y, Transplantation, 1975, 19, 382.

${ }^{9}$ Calne, R Y, Annals of Surgery, 1976, 184, 605.

10 Johnson, $\mathrm{P}$, et al, in preparation.

11 Corman, J L, et al, Gastroenterology, in press.

12 Portmann, B, et al, Gastroenterology, 1976, 70, 82.

13 Starzl, T E, et al, Surgery, Gynecology, and Obstetrics, 1976, 142, 487.

14 Starzl, T E, et al, Transplantation Proceedings, 1974, 6, 129.

${ }^{15}$ MacMaster, $\mathrm{P}$, and Herbertson, $\mathrm{B} M$, in preparation.

${ }^{16}$ Andres, G A, et al, Lancet, 1972, 1, 295.

17 Calne, R Y, et al, British Medical fournal, 167, 4, 645.
${ }^{18}$ Daniel, M R, and Wakerley, C L, British fournal of Experimental Pathology, 1976, 57, 137.

19 Davies, H, et al, fournal of Experimental Medicine, 1976, 143, 987.

20 Eddleston, A L W F, et al, Transplantation, 1973, 12, 11.

${ }^{21}$ Matas, A J, Simmons, R L, and Najarian, J S, Lancet, 1975, 1, 1277.

22 Williams, $\mathrm{R}$, in Progress in Liver Diseases, Vol V, ed H Popper and $\mathrm{F}$ Schaffner, p 418. New York, Grune and Stratton, 1976.

23 Putman, C w, et al, Fournal of the American Medical Association, 1976, 236, 1142.

24 Terblanche, J, Saunders, S J, and Louw, J H, Surgery, 1972, 71, 720.

${ }^{25}$ Starzl, T E, et al, Proceedings of the fosiah Macy fr Foundation International Conference on Liver Disease in Infancy and Childhood, 1975, in press.

26 Groth, C G, et al, Transplantation Proceedings, 1973, 5, 829.

27 Putman, C W, et al, World fournal of Surgery, in press.

${ }^{28}$ Daloze, P, et al, Transplantation Proceedings, 1975, 7, 607.

(Accepted 10 fanuary 1977)

\title{
Incidence of post-abortion psychosis: a prospective study
}

\author{
COLIN BREWER
}

British Medical fournal, 1977, 1, 476-477

\begin{abstract}
Summary
Twenty-one consultant psychiatrists participated in a prospective study of post-abortion psychosis among a population of 1333000 people. During the 15-month study only a single case was reported, concerning a woman who had a history of two previous attacks of puerperal psychosis. The incidence of post-abortion psychosis was 0.3 per 1000 legal abortions. The incidence of puerperal psychosis, which was also studied as an index of validity, was 1.7 per 1000 deliveries. This conforms with currently accepted figures and indicates that the study population was representative. I suggest that physiological changes, which are probably more profound after childbirth than after abortion, may be responsible for the higher incidence of puerperal psychosis.
\end{abstract}

\section{Introduction}

Although the incidence of serious mental disturbance after legal abortion is generally held to be low, no British studies provide any precise figures. Jansson ${ }^{1}$ reported an incidence of $19 \cdot 2$ admissions per 1000 legal abortions and $2 \cdot 7$ admissions per 1000 illegal and spontaneous abortions within 12 months of abortion, but this study related to a period (1952-6) when abortion in Sweden was not freely available. A significant proportion of those aborted had a history of serious psychiatric disorder. Jansson's findings are of doubtful relevance to conditions in Britain today since most aborted women have no such history and changing attitudes to abortion may have made it a less disturbing experience.

\footnotetext{
Department of Psychiatry, University of Birmingham, Birmingham B15 2TT

COLIN BREWER, MRCPSYCH, lecturer
}

This conclusion certainly may be drawn from a recent study in the USA by Tietze and Lewit." In a follow-up of 73000 legally aborted women they found that the incidence of "major psychiatric complications" (virtually synonymous with admission to a psychiatric ward) was $0 \cdot 2-0 \cdot 4$ per 1000 abortions. Diagnostic concepts and admission procedures in the USA, however, differ from those used here, and the follow-up period was short.

Even if the incidence of post-abortion psychosis were similar to that of puerperal psychosis-that is, between one and two per 1000 deliveries-it would be necessary to survey at least 3000 aborted women to obtain valid figures. No published British study has entailed anything like such numbers. A different approach is to find out how many women are admitted to particular psychiatric hospitals within a given period after a legal abortion and to relate it to the number of abortions performed in their catchment area populations during the study period. This method was adopted by Jansson, and the existence of reliable regional abortion statistics as a consequence of the 1967 Abortion Act enabled me to use a similar method in the present study.

\section{Method}

Twenty consultants in adult general psychiatry practising in the West Midlands Region, and the consultant in charge of the regional unit for adolescents took part in a prospective survey that began on 1 July 1975 and ended on 30 September 1976. They recorded all patients admitted under their care who had had a legal abortion during the previous three months. Patients were divided into two categories. namely - primary post-abortion psychosis (category A) or secondary post-abortion psychosis (category B). Category A was defined as "a serious disorder requiring admission, and manifesting delusions and/or hallucinations, or gross overactivity, in the absence of a previous history of significant psychiatric disorder." Category B was defined as category A but referred to women with a previous history of psychiatric disorder requiring admission to hospital.

The record form made it clear that these categories were intended to embrace "such diagnoses as mania, schizophrenia, delirium, and the more serious cases of depression." The consultants were also asked to record any patients who did not satisfy the rather narrow criteria of the two categories, but who had been legally aborted during the previous three months.

To calculate the approximate number of abortions occurring during the study period in their catchment areas, each consultant was asked to state the population for which he was responsible (excluding the 
consultant for the regional adolescent unit, whose patients came from the whole region). Some consultants had well-defined catchment areas, while others shared a population with other consultants at their hospital. In the latter cases, the population was divided by the number of consultants on the staff. In this way I could estimate the total population covered by the survey, and hence, by reference to the regional figures, calculate the probable number of abortions performed.

There were obvious sources of potential error in such calculations, although the number of consultants pooling their patients suggested that any errors would cancel out. As an independent check, however, during the first three months of the study the consultants were also asked to record comparable admissions occurring within three months of childbirth (live or stillborn). If the incidence of puerperal psychosis calculated on the same basis conformed with the results of previous surveys despite the apparently ill-defined catchment areas, it would show that the population nevertheless contained a representative number of fertile women, and that it formed a valid basis for studying the incidence of post-abortion psychosis.

\section{Results}

The 20 consultants in adult psychiatry from 14 different hospitals (a quarter of all such consultants in the region) served a total catchment area population of 1333000 people, which represented $26 \%$ of the population of the region. In 1974, the last year for which regional figures were available, 11722 abortions were performed on women resident in the West Midlands Region. ${ }^{3}$ Since then, there has been a reduction of about $6^{\circ}{ }_{0}$ in the national figures, ${ }^{4}$ and it was assumed for the calculation that the regional figure had also fallen by $6^{\circ}{ }_{0}$. During the 15 months of the study, therefore, the expected number of abortions in the study population was about 3550 .

During the first three months of the survey, the total of live and stillbirths in the region was $16750 .^{5}$ The expected number of births among the study population was 4110 . This figure was based on a catchment area population reduced by 80000 because one consultant did not record puerperal admissions. There was no reported case of post-abortion psychosis in category $\mathrm{A}$, and one case in category $\mathrm{B}$. Four cases of puerperal psychosis were reported in category A, and three in category B. No consultant reported any patient admitted within three months of an abortion who was not disturbed enough to qualify for either of the above categories. There were two admissions for less serious types of puerperal disturbance.

The incidence of post-abortion psychosis in this study was thus one in 3550 or 0.3 per 1000 abortions, while the incidence of puerperal psychosis was 7 in 4110 or 1.7 per 1000 deliveries. The difference is significant at the $2 \%$ level.

\section{Discussion}

This study shows that post-abortion psychosis is extremely uncommon and has a considerably lower incidence than puerperal psychosis. Since only one case was reported, the figure of 0.3 per 1000 must be regarded as provisional pending a study of more women. Nevertheless, the figure is strikingly similar to the one given by Tietze and Lewit ${ }^{2}$ that included a number of cases that would not have satisfied the criteria of psychosis used here. The incidence of puerperal psychosis reported here is in the middle of the range of figures cited by Jansson $^{6}$ in his review of the works on this subject, and strongly supports the validity of the results.

The single case of secondary post-abortion psychosis concerned a married woman aged 31 who had had two previous full-term pregnancies. Each was followed by a puerperal psychosis of depressive type that required admission to hospital on one occasion and electric convulsion therapy (ECT) on both. The abortion, by aspiration at seven weeks' gestation, was recommended on psychiatric grounds, and she was simultaneously sterilised. Ten days after abortion she was admitted in a depressed state, and was discharged six weeks later after a course of ECT. So far as is known, she has maintained her recovery.

One consultant reported an additional case of post-abortion psychosis (category A) in a woman whom he had seen some 18 months before the start of the study. A year later she became pregnant again and decided to go to term, but was readmitted at 24 weeks' gestation in a depressed state from which she recovered within a month.

Given that childbirth is more hazardous in psychiatric terms than abortion, two possible explanations suggest themselves. It could be said that abortion is of trivial emotional importance, and that the excess of puerperal psychosis indicates the greater emotional turmoil caused by childbirth and child-rearing, whether welcome or not. This view might be supported by studies such as that by Stevens, ${ }^{7}$ which show a greater incidence of pueperal psychosis in unmarried mothers, and by Tetlow's ${ }^{8}$ report of psychosis occurring after the adoption of children.

On the other hand, many people may feel that the termination of an unwanted pregnancy is a more melancholy occasion than the arrival of a wanted child. In most cultures childbirth is a cause for festivities; abortion-even in this allegedly permissive age-is usually not. Thus the excess of puerperal psychosis may indicate that hormonal and other "physiological" changes after childbirth-which are presumably more profound than those after abortion-are the major precipitating factors in puerperal psychosis, as Dalton ${ }^{9}$ suggests, rather than psychological disturbances. This finding has implications both for research into the aetiology of puerperal psychosis and for the management of those afflicted with it.

Both Tietze and Lewit's survey ${ }^{2}$ and the present one showed a much lower incidence of post-abortion psychosis than in Jansson's carefully conducted study. The lower incidence of serious psychiatric disorders among aborted women and changing attitudes to abortion have already been mentioned. High post-abortion admission rates may also have reflected a greater level of anxiety among psychiatrists and other doctors at a time when abortion may have been regarded with more fear than is usually the case now. Another possibility is that the Swedish study may have included a larger proportion of older, multiparous women, and of late abortions.

One possible source of error in the present study (and in Jansson's) is that a history of recent abortion may have been overlooked in some cases. Certainly it is easier to miss a recent abortion than a recent delivery, but any National Health Service abortion and any abortion performed because of a serious psychiatric disorder would generally be known to the referring family doctor, and in the study region most non-National Health Service abortions are either referred by or notified to family doctors. Furthermore, just as childbirth usually features in the conversation of puerperal psychotics, it might be expected that post-abortion psychotics would be preoccupied with some aspect of their abortion, as happened in the two cases reported here.

Childbirth may lead to psychiatric disorder after the traditional three-month puerperal period, and the same may theoretically apply to post-abortion disturbances. In practice, the consultants taking part in this survey reported that disorders apparently related to abortions in the more distant past were also rare. Nearly half of Jansson's patients were admitted within three months of their abortion.

I thank Dr Andrew Sims and Mr Peter Harvey for their help and advice, and the consultants taking part for their co-operation.

\section{References}

1 Jansson, B, Acta Psychiatrica Scandinavica, 1965, 41, 87.

2 Tietze, C, and Lewit, S, Studies in Family Planning, 1972, 3, 97.

3 OPCS Monitor. AB 76/7. London, HMSO, 1976.

4 OPCS Monitor AB/74, AB/76. London, HMSO, 1974

5 Office of Populations, Censuses, and Surveys, Population Trends, No 5. London, HMSO, 1976.

6 Jansson, B, Acta Psychiatrica Scandinavica, 1963, 39, Suppl 172.

7 Stevens, B, Social Science and Medicine, 1971, 5, 527.

8 Tetlow, C, Fournal of Mental Science, 1955, 107, 629.

9 Dalton, K, British fournal of Psychiatry, 1971, 118, 689. 